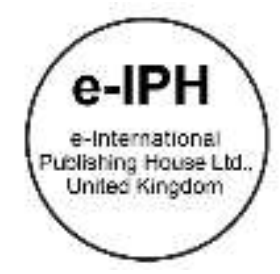

\title{
Potential for Livening Urban Areas in Developing Countries through Carfree Streets: Nairobi, Kenya
}

\author{
Anthony Murithi Njeru, Kinoshita Isami \\ Graduate School of Horticulture, \\ Chiba University, Matsudo City, 271-8510, Japan \\ afta8857@chiba-u.jp, isamikinoshita@faculty.chiba-u.jp \\ Tel: +81473088790
}

\begin{abstract}
It has been established that carfree streets in Central Business Districts (CBDs) are linked to more livable urban environments, but most studies on this topic have concentrated on developed countries. Based on data from 399 questionnaires and interviews with 6 key stakeholders, this study presents street users' reported safety, comfort, and connectivity for three street types: a typical car street, a one-way street, and a carfree street in Nairobi Kenya. Further, this study discusses the relationship between approaches of key decision makers such as the City Government and business owners against the priorities of day-to-day pedestrians.
\end{abstract}

Keywords: Streets, Carfree, Pedestrians, Central Business District

eISSN: 2398-4287 @ 2018. The Authors. Published for AMER ABRA cE-Bs by e-International Publishing House, Ltd., UK. This is an open access article under the CC BYNC-ND license (http://creativecommons.org/licenses/by-nc-nd/4.0). Peer-review under responsibility of AMER (Association of Malaysian Environment-Behaviour Researchers), ABRA (Association of Behavioural Researchers on Asians) and cE-Bs (Centre for Environment-Behaviour Studies), Faculty of Architecture, Planning \& Surveying, Universiti Teknologi MARA, Malaysia.

DOI: https://doi.org/10.21834/e-bpj.v3i8.1400

\subsection{Introduction}

In recent years, there has been an increased focus on the negative effects of overdependence on automobiles in cities of developing countries. For example, studies on pedestrian injuries in cities such as Nairobi, Kenya have depicted the great human suffering and deaths of pedestrians caused by automobiles (Ogendi, Odero, Mitullah \& Khayesi, 2013). Many studies have also demonstrated authorities' prioritisation of automobiles and the sidelining of pedestrians in many urban areas of developing countries. There is therefore a general agreement on the need to protect pedestrians from problems of automobile traffic.

However, control over motorisation in CBDs has been left to capitalist forces such as shop owners' perceived sales, clients' convenience, and city governments' parking revenues. The needs of people utilising the street spaces in daily life have thus been neglected. Congestion, traffic accidents, environmental pollution and other secondary consequences of automobile dominance such as crime have in turn negated the economic gains brought by automobiles. Compared to many developed countries, there has been little research dedicated to carfree schemes in Central Business Districts (CBDs) of cities in developing countries. Cities in developing countries have many peculiarities such as high proportions of informal traders, a large mix of vehicles including carts and motor cycles, as well as limited financial capabilities. These call for specific approaches in dealing with problems of motorization and in upholding the plight of vulnerable groups such as pedestrians.

\subsection{Aim of the study}

Based on Nairobi, the capital city of Kenya, and one of the biggest business hubs in Africa, the primary aim of this paper is to bring a better understanding on how street users experience the streets regarding the effects of automobiles in CBDs. The study attempts to 
show pedestrians' evaluation of safety, comfort and convenience in varying levels of traffic. It also evaluates pedestrians' priorities regarding automobile restrictions in the CBD and how this compares with the priorities of decision makers.

\subsection{Literature Review}

\subsection{Conflicts in use of space in streets in developing countries}

Many scholars have presented recent efforts to introduce car-free schemes in CBDs for reasons such as safety, visual attractiveness, reducing air pollution, and economic revitalization (Nieuwenhuijsen \& Khreis, 2016; Kumar \& Ross, 2006). Unfortunately, initiatives of restricting cars in major cities of developing countries are rare even though they experience similar or worse challenges compared to their developed counterparts. Ogendi, Odero, Mitullah \& Khayesi (2013) while studying pedestrian injuries in Nairobi found that pedestrians constituted the largest proportion of those admitted in hospital for road traffic injuries (59.1\%) when compared to motor vehicle passengers and motorcyclists; among motorised four-wheeler vehicles involved in collisions with pedestrians, cars lead (39.4\%) followed closely by matatu, 14-seater mini-buses (35.5\%). Even though pedestrians are the most vulnerable, most government policies in developing countries are directing funds to the affairs of motorised modes of transport while sidelining pedestrians (Kumar \& Ross, 2006; Adejumo, 2010). Meanwhile, Masuri, Isa, \& Tahir, (2012) note that most traffic crashes are a result of negative human behaviors and not inadequacies of infrastructure.

Best practices on mobility across the globe have emphasized on vulnerable people but most developing countries lag behind. For example, Daodu \& Said (2018) have observed that $70 \%$ of studies on the independent mobility of children between 2007 and 2008 were done in developed countries of Europe and little or nothing on Africa. Current research on mobility in developing countries also shows a gap in articulating issues of automobile restrictions and the effects thereof. Although there are many studies on the existing challenges, recommendations have often emphasised on improving the physical infrastructure for increased automobility. Studies regarding streets in developing countries have often focused on heritage of historical streets (Yunus, Samadi, \& Omar, 2015; Samadi, Omar \& Yunus, 2012). Others such as Sholihah \& Heath (2016) have also studied the conflicts that arise between shop owners and street vendors due to competition.

\subsection{Livability and quality of streets in CBDs}

Central Business Districts (CBDs) generally consists of a high concentration of activities such as shopping, office, cultural, administrative, entertainment, wholesales, and industries in contrast to the homogenous residential and industrial land uses outside the innermost part of towns (Funsho, Bukola, \& Omoyeni, 2013). Unlike neighborhoods, these areas have a wider variety of user groups including visitors, traders, and residents. Additionally, walking is the best way to experience these areas because of high development density and congestion that do not allow for a pleasant driving experience (Zakariah \& Ujang, 2015). The livability and quality of these streets to their users depends on a variety of factors.

Livability of urban streets regards how well a street caters to the needs of its users. Many studies have used walkability as a measure of livability due to its environmental sustainability and promotion of physical health (Shamsuddin, Hassan, \& Bilyamin, 2018; Wicramasinghe \& Dissanayake, 2017). Azmi, Karim, \& Amin (2012) have characterized walkability based on aspects of walking behavior: speed, direction, walking experience, group formation, and density. Pedestrian friendliness has also been used to measure livability (Rahman, Sakip, \& Nayan, 2018). Streets are livable if they satisfy a user's feeling of safety, comfort and convenience, as well as access and connectivity (Rahman, Sakip, \& Nayan, 2018; Zakaria \& Ujang, 2015). Additionally, Jeong, Heo, \& Jung (2015) note that intensity of shopping activities, traditional characteristics, and the sense of place attachment are key contributors of liveliness of streets.

Safety on streets is a measure of how much a street user is free from both real and subjective dangers based on factors such as the amount of vehicular traffic, presence of other street users, police security, and signs of vandalism (Rahman, Sakip, \& Nayan, 2018). Presence of people may enhance the feeling of safety although overcrowding has negative impacts due to the possibility of pickpockets and sexual harassment; the extents differ between men and women (Rahman, 2015). Sham, Omar, \& Amat, (2012) note that most women, $74.2 \%$ reported encountering crime while walking to or from public transport points in Malaysia. According to Shokoohi, Hanif, \& Dali (2012), parents' judgment of children's safety depends on the number of other pedestrians on the street.

Comfort and convenience regards the pleasantness of a street regarding elements such as weather and climate, spaciousness, and support facilities (Rahman, Sakip, \& Nayan, 2018). It is also influenced by the type of users especially the presence of students and tourists (Jalaladdini \& Oktay, 2013).

Access and connectivity regard how well a street user is able to navigate smoothly through the street and effectively reach points of interest such as bus stops; the presence of obstacles and the directness of walkways are some of the determinants (Zakariah \& Ujang, 2015). Rahman (2016) posits that a place is accessible when there is an equal opportunity for everybody to use public spaces. Wicramasinghe \& Dissanayake (2017) studying the Central Business District of Kandy in Sri-Lanka observe that presence of obstacles and flow rate are key determinants of pedestrians avoiding walkways and instead using dangerous carriageways.

\subsection{Background of the Study area}

Nairobi is the capital city of Kenya, an inland city as shown in figure 2.3.1. Its foundations as an urban area began in 1896 as a transport depot with stores and stables, and became a railway station by 1899 for the British colonial government; it had a population of 11,512 in 1906 and 108,900 in 1948 (White, Silberman \& Anderson,1948). Public transport is dominated by Matatu, 14-seater private-owned 
vans. Matatu fares fluctuate depending on demand and do not operate on a time schedule hence very unreliable; they are also a major contributor of congestion since most of the routes in the city terminate within the CBD.

White, Silberman \& Anderson (1948) note that by 1906 differentiation of Nairobi was largely based on racial segregation in addition to the Railway-related developments. Decades after the end of the British Colonial Government in 1963, there are general distinctions between the uptown on the Western side of Tom Mboya Street and the downtown on the Eastern side (figure 2.3.2): the uptown has a higher proportion of older buildings inherited from the colonial era, and is generally dominated by high-end boutiques, banks, and restaurants. The downtown is dominated by cheaper restaurants, shops for motor vehicle spare parts, electronics, clothes, and shoes; buses and matatu are also concentrated on this side. Streets in the uptown such as Mama Ngina Street have less traffic congestion compared to the Downtown as shown in figure 2.3.3. The Aga Khan Walk is the only major street within the CBD that is carfree.

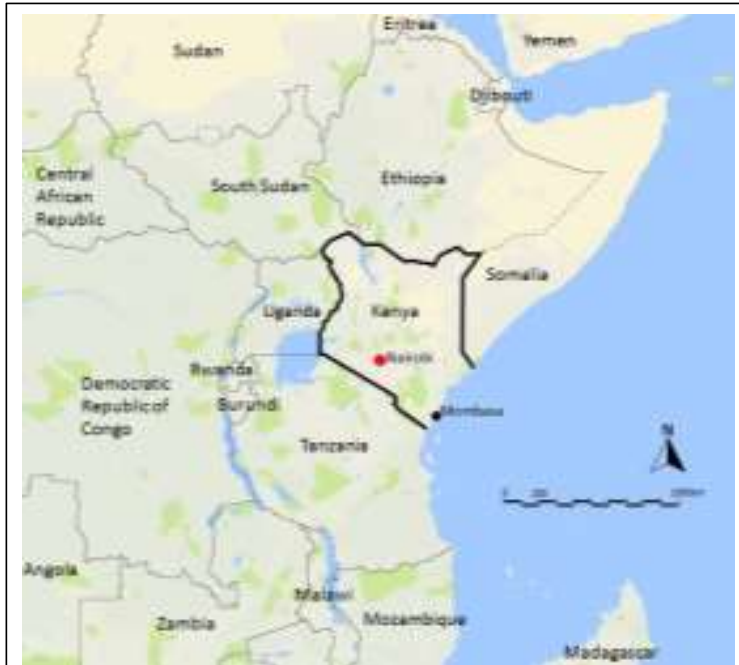

Figure 2.3.1: Location of Nairobi, Kenya.

Source: Author, adopted from GoogleMaps.

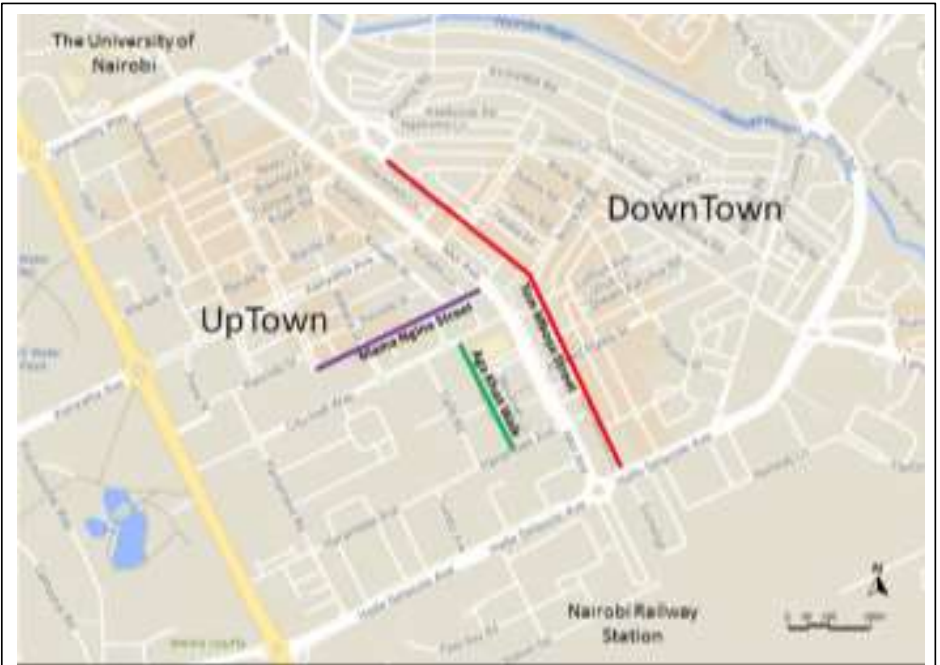

Figure 2.3.2: Street layout of the Nairobi CBD showing Tom Mboya Street, Mama Ngina Street, and Aga Khan Walk. Source: Author, adopted from

\subsection{Methodology}

This study is based on a questionnaire survey of pedestrians in Nairobi, as well as structured interviews with key stakeholders. A pilot survey with open questions was first administered on thirty one respondents to test the effectiveness of the questionnaire; some of the answers were used in the final questionnaire as choices for the close-ended questions. Traffic density and physical conditions of streets in both the downtown and the uptown areas were analysed. Due to time and financial constraints, three streets were selected. The final questionnaire consisted of four main sections: 1. respondents use characteristics such as the objective and frequency of using the street, 2. users' satisfaction on aspects of safety, comfort, and connectivity based on a Likert scale of five points, 3, attitudes towards car restrictions, and 4. respondent's personal attributes such as age and gender.

In total, 399 questionnaires were administered to pedestrians on Tom Mboya Street, a typical street with high traffic volumes (169), Mama Ngina Street, a one-way Street with minimal vehicular traffic (115), and Aga Khan Walk, a carfree street (115). In total 399 fully filled questionnaires were utilized. Structured interviews involved 6 people: 2 engineers from City Government, 1 former director of planning in the City Government, 1 former leader of the Nairobi Business District Association, and 2 academics in Planning and Landscape Architecture in Nairobi. The interviews aimed at getting a deeper understanding of the intricacies undermining the needs of pedestrians and the prioritization of automobiles.

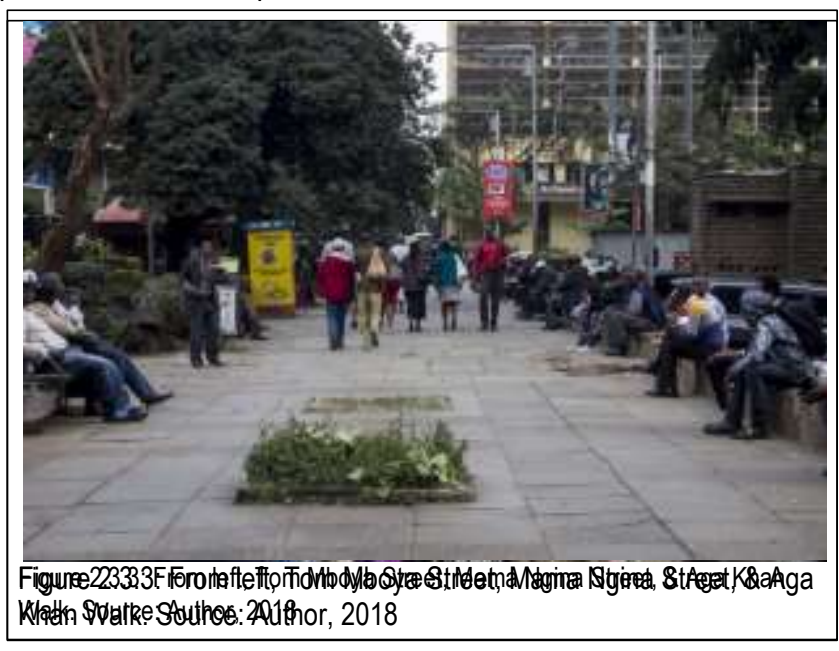

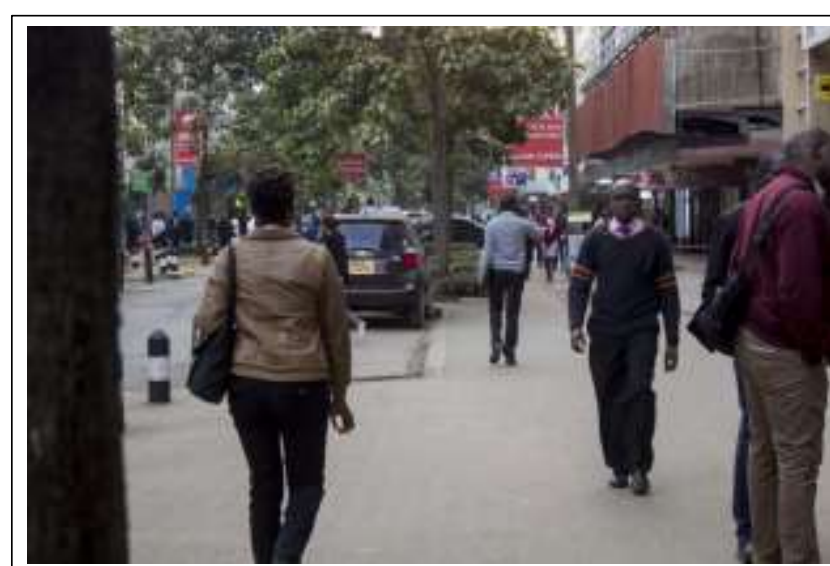

Figure 2.3.4: Mama Ngina Street. Source: Author, 2018 


\subsection{Results \& Discussion}

\subsection{Attributes of respondents}

Respondents to the questionnaires comprised of $60.3 \%$ male and $39.7 \%$ female; respondents in the 20 s-age group constituted $49.2 \%$ followed by 30 s $(23.8 \%)$. Only $28.1 \%$ of respondents own cars. Regarding street usage, $47.3 \%$ of respondents generally use the streets daily; only $6.1 \%$ were on the streets for the first time. $26.6 \%$ of respondents did not enter any establishment on the streets they were interviewed in, while $29.2 \%$ had entered restaurants. Regarding the purpose of being in the CBD, respondents who came to meet a friend comprise the largest proportion, $30.6 \%$, followed by those doing business (22\%), and those work in the CBD (20\%).

\subsection{Priorities for carfree streets}

Regarding vehicles that respondents want restricted from accessing the CBD, most respondents were concerned by matatu (41.1\%) followed by motorcycles (39.5\%), and private cars (10.6\%). Although not included among the choices, $8.7 \%$ of respondents proposed the exclusion of Hard Push Carts. Although Matatu were perceived as the greatest threat, it is clear from the interviews that most decisions to restrict Matatu have not been implemented because of the political influence of people involved in Matatu business. From interviews, a lot of the mobility problems are related to poor public transport that is dominated by low-capacity vehicles instead of buses and trains.

Regarding streets that need temporary restriction of vehicles, Tom Mboya Street leads at $40.7 \%$ among the choices given; it also leads at $35.3 \%$ regarding suggestions for permanent restrictions. Other streets mentioned are shown in figure 4.2.1. Generally, there is a greater concern for streets in the downtown area compared to those in the uptown area. The results above contradict current progress that has focused on uptown streets. Rahman, Sakip, \& Nayan (2018) also bemoan the tendency to make decisions favorable to business entities while disregarding pedestrians and vitality of streets. From interviews, political influence and funding of one of the major business owners that drove the initiative to convert Mama Ngina Street into a one-way street; the urgency was based on security considerations for high profile offices.

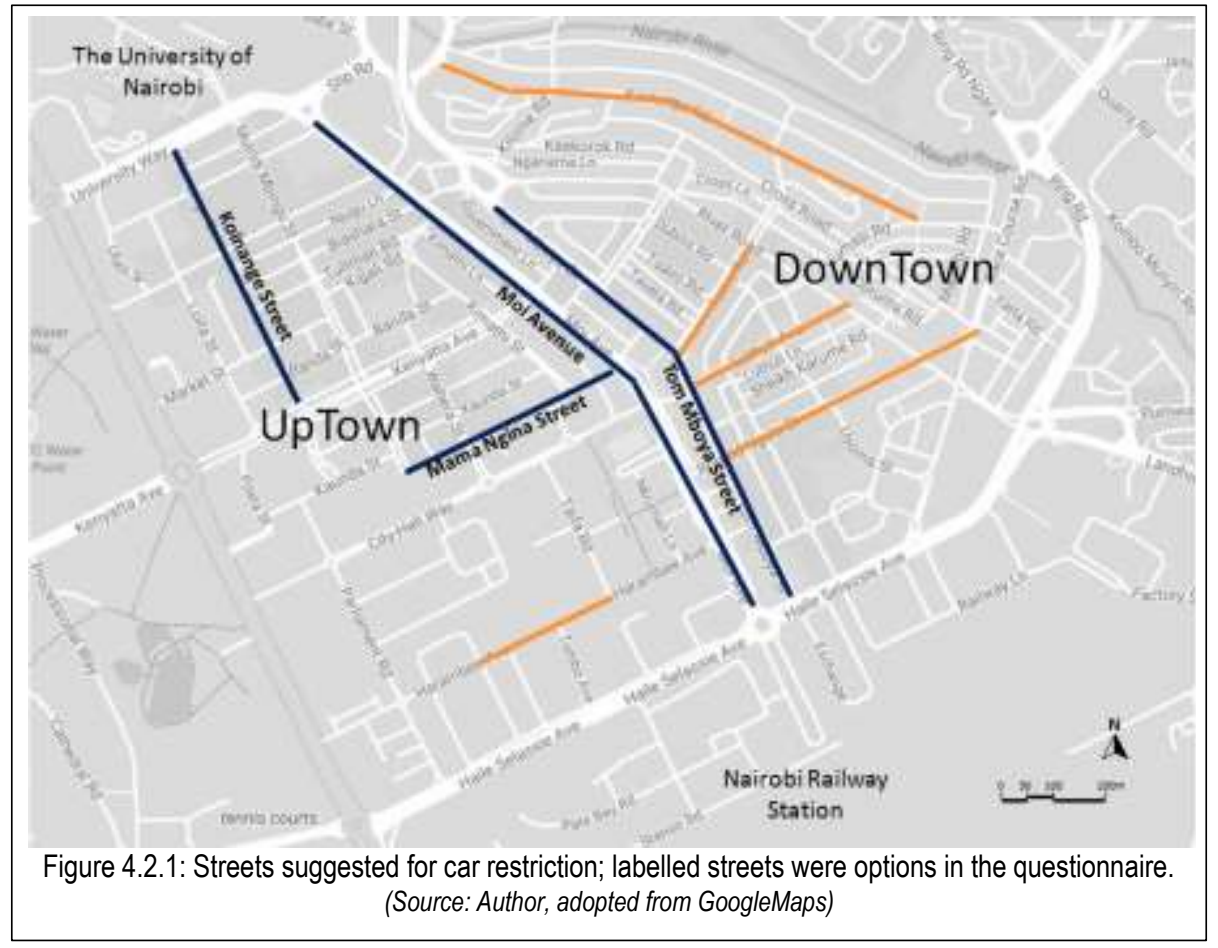

\subsection{Satisfaction with safety}

In general, respondents were most satisfied with safety on the carfree street followed by one-way street; the street with many cars has least perceived safety. Variations among the three streets were statistically significant for all variables except "safety at night" and "actions of beggars" as shown in table 4.3.0

Safety at night was evaluated unfavorably on the carfree street; this could be as a result of the trees and shrubs as well as low volumes of pedestrian traffic due to poor proximity to matatu stops. Safety at night ranks highest on the one-way street; this may be attributable to the presence of bars and restaurants that operate at night. In general, non-criminal activities of other people such as beggars and preachers were evaluated as satisfactory as compared to perceptions regarding crime and stranger danger. The ranking for activities of beggars is almost the same for the three street types. 
Table 4.3 Safety

\begin{tabular}{|c|c|c|c|c|c|c|c|}
\hline \multirow[b]{2}{*}{ Variable name } & \multicolumn{2}{|c|}{ Car Street } & \multicolumn{2}{|c|}{ One-way Street } & \multicolumn{2}{|c|}{ Carfree Street } & \multirow[t]{2}{*}{$p$ value } \\
\hline & Mean & $\begin{array}{l}\text { Std. } \\
\text { Deviation }\end{array}$ & Mean & $\begin{array}{l}\text { Std. } \\
\text { Deviation }\end{array}$ & Mean & Std. Deviation & \\
\hline Safety from strangers & 2.83 & 1.106 & 2.90 & 1.144 & 3.28 & 1.148 & $.003^{\star *}$ \\
\hline Safety from crime & 2.64 & 1.193 & 3.08 & 1.119 & 3.16 & 1.231 & $.000^{* * *}$ \\
\hline Safety from vehicular traffic & 3.21 & 1.039 & 3.14 & 1.138 & 3.66 & 1.135 & $.000^{* * *}$ \\
\hline Antisocial activities & 2.93 & 1.049 & 2.73 & 1.048 & 3.37 & 1.115 & $.000^{* * *}$ \\
\hline Safety at night & 2.79 & 1.211 & 3.07 & 1.103 & 2.87 & 1.182 & .149 \\
\hline Safety for children and elderly & 2.56 & 1.117 & 2.96 & 1.141 & 3.35 & 1.178 & $.000^{* * *}$ \\
\hline Actions of beggars & 2.37 & 1.229 & 2.54 & 1.072 & 2.47 & 1.169 & .469 \\
\hline Actions of preachers & 2.59 & 1.227 & 2.78 & 1.120 & 3.01 & 1.306 & $.020^{*}$ \\
\hline Actions of hawkers & 2.78 & 1.271 & 2.59 & 1.247 & 3.01 & 1.331 & $.049^{*}$ \\
\hline
\end{tabular}

(Source: Author)

\subsubsection{Correlation of safety against respondents' personal attributes}

When Safety is correlated against car ownership, there is a weak correlation and no statistical significance in the relationship; same for gender, age, the frequency of using the street, and objective of coming to the CBD. However, although, there is a weak correlation, level of education is statistically significant in predicting safety, $p=0.026$ as shown in table 4.3.1

Table 4.3.1: Correlation of Safety against respondents' personal attributes

\begin{tabular}{lcl}
\hline & \multicolumn{1}{c}{$\boldsymbol{R}$ value } & $\boldsymbol{p}$ value \\
\hline Car ownership & .028 & .879 \\
Gender & .112 & .123 \\
Age & .138 & .505 \\
Level of education & .195 & $.026^{*}$ \\
Frequency of using the street & .091 & .742 \\
Objective & .205 & .119 \\
\hline \multicolumn{3}{c}{${ }^{*}$ shows statistical significance $\leq 0.05$}
\end{tabular}

Table 4.4.0: Comfort

\begin{tabular}{|c|c|c|c|c|c|c|c|}
\hline \multirow[b]{2}{*}{ Variable name } & \multicolumn{2}{|c|}{ Car Street } & \multicolumn{2}{|c|}{ One-way Street } & \multicolumn{2}{|c|}{ Carfree Street } & \multirow{2}{*}{$p$ value } \\
\hline & Mean & $\begin{array}{l}\text { Std. } \\
\text { Deviation }\end{array}$ & Mean & $\begin{array}{l}\text { Std. } \\
\text { Deviation }\end{array}$ & Mean & Std. Deviation & \\
\hline Condition of pavement & 2.51 & 1.266 & 2.86 & 1.137 & 3.26 & 1.285 & $.000^{* \star *}$ \\
\hline Attractiveness of surroundings & 2.95 & 1.127 & 3.19 & 1.167 & 3.55 & 1.165 & $.000^{\star * \star}$ \\
\hline Opportunities for standing & 3.11 & 1.103 & 3.12 & 1.153 & 3.59 & 1.022 & $.001^{* * *}$ \\
\hline Opportunities for Sitting & 2.63 & 1.086 & 2.32 & 1.080 & 3.78 & 1.080 & $.000^{\star * *}$ \\
\hline Congestion/Crowding & 2.49 & 1.202 & 2.91 & 0.996 & 3.28 & 1.121 & $.000^{* * *}$ \\
\hline Ability to talk or hear & 3.10 & 1.074 & 3.27 & 1.013 & 3.68 & 1.028 & $.000^{\star * *}$ \\
\hline Free from obstacles & 2.98 & 1.189 & 3.17 & 1.070 & 3.63 & 1.066 & $.000^{* * *}$ \\
\hline Ability to participate in activities & 2.88 & 1.145 & 3.07 & 1.038 & 3.36 & 1.179 & $.002^{* *}$ \\
\hline Shade/cover from adverse weather & 2.63 & 1.226 & 2.59 & 1.215 & 2.53 & 1.280 & .788 \\
\hline Sufficient width/spaciousness & 3.02 & 1.216 & 3.39 & 1.250 & 3.43 & 1.308 & $.009^{* *}$ \\
\hline Greenery e.g. trees \& flowers & 2.92 & 1.241 & 2.92 & 1.239 & 3.52 & 1.235 & $.000^{\star * *}$ \\
\hline Pleasantness regarding smell & 2.75 & 1.173 & 3.21 & 1.260 & 3.00 & 1.363 & $.012^{*}$ \\
\hline Pleasantness regarding noise & 2.37 & 1.106 & 3.04 & 1.085 & 3.24 & 1.219 & $.000^{\star * *}$ \\
\hline General cleanliness & 2.79 & 1.250 & 3.11 & 1.226 & 3.13 & 1.383 & $.046^{*}$ \\
\hline Mix of uses such as shops/restaurants & 3.25 & 1.107 & 3.19 & 1.138 & 3.63 & .984 & $.003^{* *}$ \\
\hline Availability of dustbins & 2.65 & 1.253 & 2.83 & 1.051 & 2.78 & 1.354 & .442 \\
\hline Availability of toilets & 2.61 & 1.203 & 2.27 & 0.947 & 3.16 & 1.295 & $.000^{\star * *}$ \\
\hline Opportunities to interact with others & 3.03 & 1.139 & 3.12 & 1.053 & 3.70 & .976 & $.000^{* * *}$ \\
\hline Liveliness of the street & 3.12 & 1.135 & 3.20 & 1.060 & 3.75 & 1.091 & $.000^{\star * *}$ \\
\hline
\end{tabular}

${ }^{*}$ shows statistical significance $\leq 0.05$

${ }^{* *}$ shows statistical significance $\leq 0.01$ (Source: Author)

\subsection{Satisfaction with Comfort and Convenience}

In general, the carfree street, Aga Khan walk is ranked higher in terms of satisfaction on most elements of comfort and convenience, followed by the one-way street, and lastly, the street with cars. Variations among Car Street, One-way Street, and the Carfree street were statistically significant for all variables except satisfaction with "shade" and "dustbins" as shown in table 4.4.0.

Opportunities for sitting on the carfree street have the highest score in the whole set; seating ranks poorly in the other two street types. The street is approximately 20 metres wide and extends for around 300 meters from City-Hall way to Harambee Avenue and has street furniture. In addition to pedestrian movement and sitting, it is host to various stationary activities such as music and theatre performances as well as street vendors. 
4.4.1 Correlation of Comfort against respondents' personal attributes

When Comfort is correlated against car ownership, there a weak correlation and no statistical significance in the relationship; same for gender, age, level of education, frequency of using the street, and objective of coming to the CBD as shown in figure 4.4.1.

\begin{tabular}{|c|c|c|}
\hline & $R$ value & p value \\
\hline Car ownership & .110 & .196 \\
\hline Gender & .073 & .483 \\
\hline Age & .177 & .290 \\
\hline Level of education & .151 & .284 \\
\hline Frequency of using the street & .086 & .848 \\
\hline Objective & .177 & .488 \\
\hline
\end{tabular}

\subsection{Satisfaction with Access and Connectivity}

In general, respondents are more satisfied with access and connectivity for the carfree street compared to the one-way street; the street with cars ranks lowest in regard to access and connectivity. Variations among Car Street, One-way Street, and the Carfree street were statistically significant for all variables except satisfaction with "access to destination," and "access to matatu/bus stop" as shown in figure 4.5.0. The variable with highest average score in this set is Carfree Street's "Access by foot." The one-way street ranks lowest with regards to access to bus stop since the uptown area is not served by public transport.

\begin{tabular}{|c|c|c|c|c|c|c|c|}
\hline \multirow[b]{2}{*}{ Variable name } & \multicolumn{2}{|c|}{ Car Street } & \multicolumn{2}{|c|}{ One-way Street } & \multicolumn{2}{|c|}{ Carfree Street } & \multirow[t]{2}{*}{$p$ value } \\
\hline & Mean & $\begin{array}{l}\text { Std. } \\
\text { Deviation }\end{array}$ & Mean & $\begin{array}{l}\text { Std. } \\
\text { Deviation }\end{array}$ & Mean & Std. Deviation & \\
\hline Ease of accessing the street on foot & 3.01 & 1.221 & 3.20 & 1.166 & 3.87 & 1.019 & $.000^{\star * *}$ \\
\hline No physical barriers e.g. walls \& fences & 3.07 & 1.078 & 3.15 & 1.084 & 3.64 & 1.063 & $.000^{* * *}$ \\
\hline No need to cross busy traffic street & 2.81 & 1.157 & 3.01 & 1.037 & 3.51 & 1.173 & $.000^{\star * *}$ \\
\hline Directness of the street & 3.31 & 1.000 & 3.28 & .944 & 3.62 & 1.057 & $.021^{*}$ \\
\hline Access to your destination & 3.48 & 1.004 & 3.38 & 1.130 & 3.58 & 1.059 & .404 \\
\hline Access to matatu/bus stage & 3.22 & 1.160 & 2.94 & 1.188 & 3.10 & 1.329 & .169 \\
\hline Access to car parking & 2.64 & 1.230 & 2.68 & 1.062 & 3.48 & 1.275 & $.000^{\star * *}$ \\
\hline Connection with neighbouring streets & 3.36 & 1.171 & 3.28 & 1.068 & 3.65 & 1.006 & $.030^{*}$ \\
\hline Visibility of other activities from the street & 3.16 & 1.162 & 3.13 & 1.140 & 3.53 & 1.107 & $.012^{*}$ \\
\hline
\end{tabular}

${ }^{*}$ shows statistical significance $\leq 0.05 \quad{ }^{* *}$ shows statistical significance $\leq 0.01 \quad{ }^{* * *}$ shows statistical significance $\leq 0.001$

(Source: Author)

\subsubsection{Correlation of Connectivity against respondents' personal attributes}

When Comfort is correlated against car ownership, there is a weak correlation and no statistical significance in their relationship; the same goes for gender, age, level of education, the frequency of using the street, and objective of coming to the CBD as shown in table 4.5.1.

Table 4.5.1: Correlation of Connectivity against respondents' personal attributes

\begin{tabular}{lll}
\hline & $R$ value & $p$ value \\
\hline Car ownership & .134 & .052 \\
Gender & .095 & .231 \\
Age & .168 & .237 \\
Level of education & .128 & .375 \\
Frequency of using the street & .148 & .208 \\
Objective & .145 & .649 \\
\hline \multicolumn{2}{c}{ (Source: Author) }
\end{tabular}

4.6.0 Correlation of Safety, Comfort and Connectivity in predicting the livability of the streets

The relationship between safety, comfort, and convenience, and connectivity was done by computing the Pearson correlation as represented in table 4.6.1. A strong positive correlation was found between Safety and Comfort, $r=.587$ as well as between Comfort and Connectivity, $r=.676$. There was a moderate correlation between Safety and Connectivity, $r=.475$. These results show a stronger correlation to a study by Zakaria \& Ujang (2015) that established .492, .499, and .448 respectively in their study on the comfort of walking in Kuala Lumpur.

Table 4.6.1: Correlation of Safety, Comfort, \& Convenience, and Access \& Connectivity

\begin{tabular}{c|c|c|c}
\hline & 1 & 2 & 3 \\
\hline 1 Safety & --- & $.587^{* *}$ & $.475^{* *}$ \\
\hline 2 Comfort \& Convenience & $.587^{* *}$ & $-\cdots$ & $.676^{* *}$ \\
\hline 3 Access \& Connectivity & $.475^{* *}$ & $.676^{* *}$ & $\cdots$ \\
\hline \multicolumn{2}{c|}{${ }^{* *}$. Correlation is significant at the 0.01 level } \\
(Source: Author)
\end{tabular}


Although studies have shown high density of people enhances vibrancy of a street (Samadi, Yunus, Omar, \& Bakri (2015), this study demonstrates that automobiles are hindrance to the enjoyment of street spaces. Even though Tom Mboya street is very vibrant, pedestrians evaluated it negatively for safety, comfort and connectivity. On the other hand, the potential in a carfree street like Aga Khan walk is not exploited optimally because it is situated away from the main sources of pedestrian traffic. Unlike other studies that have found the influence of respondents such as gender and age on perceptions of the street environment (Bohari, Bachok, \& Osman, 2016; Rahman, 2015), this study did not establish such.

\subsection{Prioritisation of automobiles by decision makers}

From the interviews, the city government of Nairobi and the national government have done little to build the financial and human resource capacity required to articulate the affairs of pedestrians. Sidelining of planners and landscape architects has undermined design of high quality streets; power plays among government agencies in allocation of funds and responsibilities have also undermined implementation of projects that could improve the welfare of pedestrians. Major decisions have not been based on research but have the political and financial impetus of business owners hence a disregard for vulnerable groups. Illegalising of informal trade activities such hawking and peddling of goods instead of negotiated arrangements for time and space has also generated conflicts on street spaces. Ultimately, as Ahmed (2017) reiterates, it is difficult to achieve equitable balance of street space without allowing street compromises between streets' function for movement and streets' function as open spaces. The huge gap between normative approaches of decision makers (mostly car users) and the experiences of low income earners alienates mobility policy from reality.

\subsection{Conclusion \& Recommendations}

This study attempted to explain the potentials and challenges in initiating carfree schemes for cities in developing countries by evaluating three streets in Nairobi with varying density of vehicular traffic. The results depict the importance of understanding various elements of three composite variables, safety, comfort and connectivity of streets in enhancing livability. It is clear that users' perception of safety, comfort, and connectivity varies greatly among the three street types: carfree street (Aga Khan Walk) ranks highest followed by the oneway Street (Mama Ngina Street), while the street with many cars (Tom Mboya Street) ranks lowest regarding users' satisfaction with the three variables. However, as Jalaladdini \& Oktay (2013) note, the vitality of public spaces is not based on a single reason but may vary from one street to another. The study therefore does not exclusively attribute the key differences in the results to the number of cars.

This study contributes to the current body of knowledge by exposing the incongruence between pedestrian's perceptions on their daily use of streets and the priorities of key decision makers such as the Nairobi City Government and the business owners. It demonstrates that efforts at restricting automobile access and circulation have not been applied where the greatest need is-reducing matatu access for streets in the downtown area. Since Matatu stops are major generators of human traffic, reducing automobile restriction should be in phases otherwise the reclaimed streets will be abandoned. Adoption of reliable high-capacity public transport will ensure that people can easily access the CBD from other places and then connect within the CBD on foot in comfort and safety from traffic dangers. Ultimately, although streets in Nairobi are currently designed in favour of access and flow of automobile traffic and not pedestrians, the negative effects are felt by both. Since this study relied on one city, and did not find significant influences of respondents' attributes such as level of education, future studies on carfree schemes for other developing and developed countries are necessary in order to show the influence of development status on perceptions towards safety, comfort and connectivity.

\section{Acknowledgements}

This study was carried out under the Japanese Government Scholarship (MEXT). The authors would like to acknowledge Chiba University, for facilitating the research.

\section{References}

Ahmed, N. O. (2017). Towards an approach to humanize the street environment: reconciling pedestrian-vehicle relationship. International Journal of Architecture and Urban Studies, 29.

Azmi, D. I., Karim, H. A., \& Amin, M. Z. M. (2012). Comparing the walking behaviour between urban and rural residents. Procedia-Social and Behavioral Sciences, 68, 406-416.

Adejumo, T. (2010). Bikabilty In Metropolitan Lagos: A Conceptualization of Eco Friendly Transportation Alternative. na.

Bohari, Z. A., Bachok, S., \& Osman, M. M. (2016). Simulating the pedestrian movement in the public transport infrastructure. Procedia-Social and Behavioral Sciences, 222, 791-799.

Daodu, T., \& Said, I. (2018). An Appraissal of Independent Mobility towards Advancing Child-friendly Military Barrack Community Milieu in Developing Countries. Environment-Behaviour Proceedings Journal, 3(7), 3-11.

Funsho, S. R., Bukola, A., \& Omoyeni, F. (2013). Planning a functional city centre in a physiographic constrained landscape: A case study of Lokoja, Nigeria. African Journal of Environmental Science and Technology, 7(8), 728-737. 
Jalaladdini, S., \& Oktay, D. (2013). Interrogating vitality of the streets in two Cypriot Towns. Asian Journal of Environment-Behaviour Studies, 4(11), 63-73.

Jeong, Y., Heo, J., \& Jung, C. (2015). Behind the bustling street: Commercial gentrification of Gyeongridan, Seoul. Procedia-Social and Behavioral Sciences, 170, 146154.

Kumar, S., \& Ross, W. (2006). Effects of pedestrianisation on the commercial and retail areas: study in Khao San road, Bangkok. Splintered urbanism.

Masuri, M. G., Isa, K. A. M., \& Tahir, M. P. M. (2012). Children, youth and road environment: road traffic accident. Procedia-Social and Behavioral Sciences, 38, 213-218.

Nieuwenhuijsen, M. J., \& Khreis, H. (2016). Car free cities: pathway to healthy urban living. Environment international, 94, 251-262.

Ogendi, J., Odero, W., Mitullah, W., \& Khayesi, M. (2013). Pattern of pedestrian injuries in the city of Nairobi: implications for urban safety planning. Journal of Urban Health, 90(5), 849-856.

Rahman, N. A., Sakip, S. R. M., \& Nayan, N. M. (2018). A User-Friendly Shopping Street. Asian Journal of Quality of Life, 3(10), 1-8.

Rahman, N. A., Ghani, I., Bahaluddin, A., \& Hussain, N. H. (2017). The Need for Good Social Behavior through People Friendly Urban Streets. Environment-Behaviour Proceedings Journal, 2(5), 469-477.

Rahman, N. A., Shamsuddin, S., \& Ghani, I. (2015). What Makes People Use the Street?: Towards a liveable urban environment in Kuala Lumpur city centre. ProcediaSocial and Behavioral Sciences, 170, 624-632.

Samadi, Z., Omar, D., \& Yunus, R. M. (2012). On-street visual analysis on outdoor space of Jalan Hang Jebat, Melaka. Procedia-Social and Behavioral Sciences, 68, 353-362.

Samadi, Z., Yunus, R. M., Omar, D., \& Bakri, A. F. (2015). Experiencing urban through on-street activity. Procedia-Social and Behavioral Sciences, $170,653-658$.

Sham, R., Omar, N., \& Amat, D. W. (2012). Hot spot urban crime area for woman travellers. Procedia-Social and Behavioral Sciences, $68,417-426$.

Shamsuddin, S., Hassan, N. R. A., \& Bilyamin, S. F. I. (2018). Walkable in Order to be Liveable. Journal of Asian Behavioural Studies, 3(7), $165-172$.

Shokoohi, R., Hanif, N. R., \& Dali, M. M. (2012). Children walking to and from school in Tehran: Associations with neighbourhood safety, parental concerns and children's perceptions. Procedia-Social and Behavioral Sciences, 38, 315-323.

Sholihah, A. B. S., \& Heath, T. (2016). Traditional Streetscape Adaptability: Urban gentrification and endurance of business. Environment-Behaviour Proceedings Journal, 1(4), 132-141.

White, L. W. T., Silberman, L., \& Anderson, P. R. (1948). Nairobi, Master Plan for a Colonial Capital: A Report Prepared Fr the Municipal Council of Nairobi. HM Stationery Office.

Wicramasinghe, V., \& Dissanayake, S. (2017). Evaluation of pedestrians' sidewalk behavior in developing countries. Transportation research procedia, 25, 4068-4078.

Yunus, R. M., Samadi, Z., \& Omar, D. (2015). Making of 'Great Heritage Street'. Procedia-Social and Behavioral Sciences, 168, 365-372.

Zakaria, J., \& Ujang, N. (2015). Comfort of walking in the city center of Kuala Lumpur. Procedia-Social and Behavioral Sciences, 170, 642-652. 